\title{
Wetting Characteristics of Different Types of Liquid on Particulate Composite Materials
}

\author{
by
}

\author{
Kentaro YamauchI ${ }^{*}$, Goro YamauchI ${ }^{* *}$ and Kenichi TAKaI ${ }^{* * *}$
}

\begin{abstract}
The particulate composite model derived to explain the high contact angle of water on the water repellent particulate composite materials was applied for the contact angle of other types of liquid such as methylene iodide and $\alpha$-bromonaphthalene on the particulate composite materials. By substituting the experimental data of contact angle of water, methyleneiodide and $\alpha$-bromonaphtalene to the formula of this model, following results were obtained. For water case, the more the PTFE volume fraction, the more area of PTFE surface is covered by air and that $100 \%$ of binder surface can be covered by water. For methylene iodide case, both PTFE and binder are covered thoroughly by methylene iodide for all the PTFE volume fraction. For $\alpha$-bromonaphtalene case, the more the PTFE volume fraction, the more area of PTFE surface is covered by air and that $100 \%$ of binder surface can be covered by $\alpha$-bromonaphtalene. By assuming that binder is covered by each of liquid, the contact angle of three different types of liquid on the PTFE particulate composites material can be skeptically expressed using the parameters of PTFE volume fraction and liquid coverage of PTFE.
\end{abstract}

Key words : Polymer base, Composite material, Coating material, Contact angle, Water repellent

\section{Introduction}

PTFE particle dispersed water repellent particulate composite material was developed for the application of snow sticking free antenna in snowy area in Japan. ${ }^{1) ~ 3)}$ Wetting properties of this composite material including deteriorating mode of water repellency were reported. ${ }^{4)} \sim 5$ ) Application of this composite material to water repellent mobile phone microphone was tried. ${ }^{6) \sim 7)}$ The application area of PTFE particle dispersed water repellent composite material has been still expanding in accordance with the improvement of this material. ${ }^{8)}$ The further improvement of the PTFE particulate dispersed water repellent composite material needs thorough understanding of the surface characterization of this material. In pursuit of the thorough understanding, wetting characteristics of different types of liquid on the PTFE particulate dispersed composite materials were studied.

The particulate composite mode ${ }^{9)}$ was developed to explain the high contact angle of water on the water repellent particulate composite material. ${ }^{4)}{ }^{5)}$ This composite material is composed of the small molecular weight politetrafluoroethylene (PTFE) particles and polivinyldenfluoride (PVdF) binder. The contact angle of PTFE is $110^{\circ}$ and that of the binder is $80^{\circ}$. Therefore the contact angle of this PTFE particulate composite material was predicted to be between $110^{\circ}$ and $80^{\circ}$.

On the contrary, the actual contact angle of the PTFE composite material is much larger than that of $100 \%$ PTFE, $150^{\circ}$. The existence of binder makes the contact angle lower. So the new mechanism of the high contact angle of water on the particulate composite material has been expected to explain the high contact angle of more than $150^{\circ}$.

The authors derived a formula that explains the high contact angle of the water repellent material taking into account the surface roughness, surface heterogeneity together with existence of air between water and the surface of the water repellent material. The aim of this study is to confirm the validity of the derived formula by measuring the contact angle of three different liquids each of which has different composition of dispersion, polar and hydrogen bonding components of surface free energy.

\section{Theory for contact angle}

The water repellent material is the composite material with small molecular weight PTFE particles dispersed in PVdF binder as shown in Fig. 1.9)

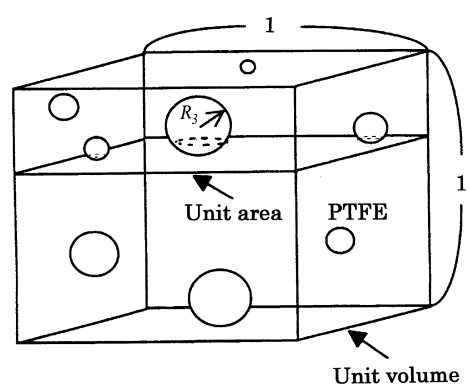

Fig. 1 Spherical PTFE particles are dispersed in unit volume.

$\dagger \quad$ Received Mar 15, 2010 (C) 2011 The Society of Materials Science, Japan

* $\quad$ Collaborative Research Center, Daido Univ., Minami-ku, Nagoya, 457-8530 Japan

* $\quad$ Member : Dept. Information Design, Daido Univ., Minami-ku, Nagoya, 457-8530 Japan

$* * * \quad$ Dept. of Mech. Eng., Sophya Univ., Chiyoda-ku, Tokyo, 102-8554 Japan 
The structure of this material is expressed by the following particulate composite model. ${ }^{9)}$

(1) PTFE particle is sphere.

(2) Number of PTFE particles per unit volume is $\mathrm{N}_{3}$.

(3) The distribution of PTFE particle radius $R_{3}$ is expressed by a function $\mathrm{F}_{3}\left(\mathrm{R}_{3}\right)$, which satisfies the following relation.

$$
\int_{0}^{\infty} F_{3}\left(R_{3}\right) d R_{3}=1
$$

On this basis, the volume fraction of PTFE particles, $\mathrm{f}_{3}$, is obtained as follows.

$$
\mathrm{f}_{3}=\mathrm{N}_{3} \int_{0}^{\infty} 4 \pi / 3 \times R_{3}^{3} F_{3}\left(R_{3}\right) d R_{3}=4 \pi \mathrm{N}_{3} / 3 \int_{0}^{\infty} R_{3}^{3} F_{3}\left(R_{3}\right) d R_{3}
$$

When the particulate composite material is cut by a plane, circles emerge on the plane. Geometry of a dispersed particle is schematically shown in Fig. $2 .{ }^{9)}$ Here, $\mathrm{R}_{2}$ is radius of a circle on the plane.

The area fraction of PTFE circles on the section plane, $\mathrm{f}_{2}$, is obtained as follows.

Among particles which are sectioned by a plane, the number of particles with radius between $R_{3}$ and $R_{3}+d R_{3}$ is

$$
\left[\left\{\mathrm{R}_{3}-\left(-\mathrm{R}_{3}\right)\right\} / 1\right] \times \mathrm{N}_{3} \mathrm{~F}\left(\mathrm{R}_{3}\right) \mathrm{dR}_{3}=2 \mathrm{R}_{3} \mathrm{~N}_{3} \mathrm{~F}\left(\mathrm{R}_{3}\right) \mathrm{dR}_{3}
$$

Number of circles per unit section plane, $\mathrm{N}_{2}$, is obtained by integrating the above equation.

$$
\mathrm{N}_{2}=\int_{0}^{\infty} 2 R_{3} N_{3} F_{3}\left(R_{3}\right) d R_{3}=2 \mathrm{~N}_{3} \int_{0}^{\infty} R_{3} F_{3}\left(R_{3}\right) d R_{3}
$$

Getting the probability that the circle radius $R_{2}$ exists between $R_{2}$ and $R_{2}+d R_{2}$, the product of this probability and $\mathrm{N}_{2}$ shows the number of spherical particles with radius between $R_{3}$ and $R_{3}+d R_{3}$. The area fraction $f_{2}$ is obtained by integrating the product of this number and $\pi \mathrm{R}_{2}^{2}$.

$$
\mathrm{f}_{2}=\mathrm{N}_{3} \int_{0}^{\infty} 4 \pi / 3 \times R_{3}^{3} F_{3}\left(R_{3}\right) d R_{3}=4 \pi \mathrm{N}_{3} / 3 \int_{0}^{\infty} R_{3}^{3} F_{3}\left(R_{3}\right) d R_{3}=\mathrm{f}_{3}
$$

In the same manner, the spherical segment area $f_{s}$ of the dispersed particles is obtained assuming particles are from fully berried position, partly berried position up to on a plane position.

$$
\mathrm{f}_{\mathrm{s}}=4 \pi \mathrm{N}_{3} \int_{0}^{\infty} R_{3}^{3} F_{3}\left(R_{3}\right) d R_{3}=3 \mathrm{f}_{3}
$$

As the areal fraction of PTFE is $\mathrm{f}_{2}$, the areal fraction of binder is $\left(1-f_{2}\right)=\left(1-f_{3}\right)$.

In case the spherical segment area is taken into account,

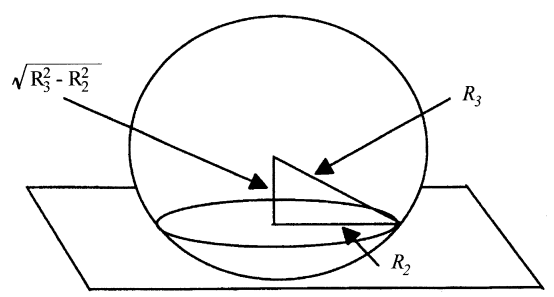

Fig. 2 A dispersed particle sectioned by plane. the binder area is $\left(1-\mathrm{f}_{3}\right)$, and the spherical segment area of PTFE is $f_{s}=3 f_{3}$. The ratio of the binder area to the spherical segment area of PTFE is

$$
\left(1-f_{3}\right): 3 f_{3} \text {. }
$$

Therefore, the areal fraction of PTFE is

$$
3 \mathrm{f}_{3} /\left(1+2 \mathrm{f}_{3}\right) \text {. }
$$

The area fraction of binder is

$$
\left(1-f_{3}\right) /\left(1+2 f_{3}\right) \text {. }
$$

Then,

$$
3 f_{3} /\left(1+2 f_{3}\right)+\left(1-f_{3}\right) /\left(1+2 f_{3}\right)=1 .
$$

It should be noted that this relation is independent of the type of particle distribution function.

To explain the wetting characteristics of the water repellent material, the model of the particular composite materials was mathematically formulated on the basis of Wentzel's equation for rough surface ${ }^{10)}$ and Cassie's equation for heterogeneous surface ${ }^{11)}$ The details of the theory were described elsewhere. ${ }^{9)}$ The wetting characteristics of material were firstly described by the contact angle of water by Young. ${ }^{12)}$ In the hydrophobic material, the existence of surface roughness makes the contact angle larger. ${ }^{10)}{ }^{13)}$ The ultimate rough surface is fractal surface. ${ }^{14)}$ The contact angle of 174 degree was observed on the fractal surface. ${ }^{15)}$ Bico et $\mathrm{al}^{16)}$ reported the wetting of textured surface. They discussed quantitatively the wetting of a solid textured by a designed roughness. Both the hydrophobic and the hydrophilic case were described. They studied Wenzel's type of wetting for rough surface, not Cassie's type of wetting for heterogeneity of the surface. The authors derived the equation of contact angle of a particulate composite material taking into account both Wenzel's type of wetting and Cassie's type of wetting. ${ }^{9)}$ From the application view point, both hydrophobic property and sticking property are needed. ${ }^{1) \sim 4)}$ This is the reason why hydrophobic PTFE particles are dispersed in the binder that sticks to the substrate in this study.

The contact angle of a particulate composite material is shown below. ${ }^{9}$

$$
\cos \theta_{a s}=\frac{3 f_{p}\left\{f_{p w}\left(1+\cos \theta_{p}\right)-1\right\}}{\left(1+2 f_{p}\right)}+\frac{\left(1-f_{p}\right)\left\{f_{b w}\left(1+\cos \theta_{b}\right)-1\right\}}{\left(1+2 f_{p}\right)}
$$

where $\theta_{\text {as }}$ : Contact angle of a particulate composite material

$f_{p} \quad$ : Volume fraction of PTFE particles

$f_{p w}$ : Ratio of water coverage of PTFE

$\mathrm{f}_{\mathrm{bw}}$ : Ratio of water coverage of binder

$\theta_{\mathrm{p}}:$ Contact angle of PTFE

$\theta_{\mathrm{b}}:$ Contact angle of binder

In the following sections, $\mathrm{f}_{\mathrm{pm}}, \mathrm{f}_{\mathrm{bm}}, \mathrm{f}_{\mathrm{p} \alpha}$ and $\mathrm{f}_{\mathrm{b} \alpha}$ instead of $f_{p w}$ and $f_{b w}$, are introduced for the contact angle of methylene iodide and $\alpha$-bromonaphthalene respectively. 
$\mathrm{f}_{\mathrm{pm}}$ : Ratio of methylene iodide coverage of PTFE

$\mathrm{f}_{\mathrm{bm}}$ : Ratio of methylene iodide coverage of binder

$\mathrm{f}_{\mathrm{p} \alpha}$ : Ratio of $\alpha$-bromonaphthalene coverage of PTFE

$\mathrm{f}_{\mathrm{b} \alpha}$ : Ratio of $\alpha$-bromonaphthalene coverage of binder

Suffix $_{\mathrm{w}}$ is for water. Suffix $\mathrm{x}_{\mathrm{m}}$ is for methylen iodide. Suffix $_{\alpha}$ is for $\alpha$-bromonaphtalene.

\section{Experimental}

\section{1 Sample preparation}

The mixture of PTFE particles and polyvinyliden fluoride with 20 80vol.\% PTFE together with butyl acetate was sprayed over the fiber reinforced plastic (FRP) substrate. A dispersed particulate composite material about $5 \mu \mathrm{m}$ in thickness was formed by one time spray. About $15 \mu \mathrm{m}$ thick particulate composite material formed by three times spray covers fully the FRP substrate. No influence from the FRP substrate is observed on the particulate composite material surface which was to be characterized. The composite material is ready for contact angle measurement 24 hours after butyl acetate dried out.

\subsection{Contact angle measurement}

Contact angles of water, methylene iodide and $\alpha-$ bromonaphtalene on the PTFE particulate composites were measured by an automatic contact angle measurement apparatus (Kyowa Kaimen Kagaku CAZ). About $3 \mu \mathrm{L}$ of liquid droplet from syringe was put on the sample. Then contact angle of liquid droplet with equilibrium position was measured automatically as follows.

The height of liquid droplet, a, and the diameter of liquid droplet contact circle diameter, b, are detected and the contact angle of the liquid, $\theta$, is automatically calculated using the following relation .

$$
\sin (\theta / 2)=\mathrm{a} / \sqrt{\mathrm{a}^{2}+(\mathrm{b} / 2)^{2}}
$$

The surface free energy of liquids is shown in Table $1^{17)}$.

Table 1 Surface free energy of liquids.

\begin{tabular}{|l|r|r|r|r|}
\hline & \multicolumn{1}{|c|}{$\begin{array}{c}\gamma_{\mathrm{d}} \\
(\mathrm{mN} / \mathrm{m})\end{array}$} & $\begin{array}{c}\gamma_{\mathrm{p}} \\
(\mathrm{mN} / \mathrm{m})\end{array}$ & $\begin{array}{c}\gamma_{\mathrm{h}} \\
(\mathrm{mN} / \mathrm{m})\end{array}$ & $\begin{array}{c}\gamma \\
(\mathrm{mN} / \mathrm{m})\end{array}$ \\
\hline $\begin{array}{l}\alpha \text {-bromo- } \\
\text { naphthalene }\end{array}$ & 44.4 & 0.2 & 0 & 44.6 \\
\hline $\begin{array}{l}\text { methylene } \\
\text { iodide }\end{array}$ & 46.8 & 4.0 & 0 & 50.8 \\
\hline water & 29.1 & 1.3 & 42.4 & 72.8 \\
\hline
\end{tabular}

Notations are shown below.

$\gamma_{\mathrm{d}}$ : Dispersion force component of surface free energy

$\gamma_{\mathrm{p}}$ : Polar force component of surface free energy

$\gamma_{\mathrm{h}}$ : Hydrogen bonding component of surface free energy

$\gamma$ : Total surface energy

$\gamma$ is the sum of $\gamma_{\mathrm{d}}, \gamma_{\mathrm{p}}$ and $\gamma_{\mathrm{h}}$.

$$
\gamma=\gamma_{\mathrm{d}}+\gamma_{\mathrm{p}}+\gamma_{\mathrm{h}}
$$

\section{Results}

\section{1 Contact angle of water}

Contact angle of three different liquids is shown in Fig. 3.

The contact angle of water increases with increasing PTFE volume fraction. At 90\% PTFE, the contact angle of the water repellent material reaches much higher value than that of $100 \% \mathrm{PTFE}$ of $110^{\circ}$. Therefore, this high contact angle cannot be explained by the existence of hydrophobic PTFE only.

The formula (6) in the former section contains the parameters of $f_{p w}$ and $f_{b w}$ to explain the high contact angle. By substituting experimental value of the contact angle of water, $110^{\circ}$ for $\theta_{\mathrm{p}}$ and $81.5^{\circ}$ for $\theta_{\mathrm{b}}$, corresponding experimentally observed contact angle for $\theta_{\text {as }}$, the relation of unknown parameters $\mathrm{f}_{\mathrm{pw}}$ and $\mathrm{f}_{\mathrm{bw}}$ is obtained as following.

$$
\begin{array}{llll}
f_{b w}=-0.42 f_{p w}+1.42 & \text { for } & f_{p}=0.2 \\
f_{b w}=-1.12 f_{p w}+2.07 & \text { for } & f_{p}=0.4 \\
f_{b w}=-2.51 f_{p w}+1.49 & \text { for } & f_{p}=0.6 \\
f_{b w}=-6.74 f_{p w}+1.49 & \text { for } & f_{p}=0.8 \\
f_{b w}=-15.1 f_{p w}+2.98 & \text { for } & f_{p}=0.9
\end{array}
$$

But the specific value of $f_{p w}$ and $f_{b w}$ cannot be obtained from the contact angle measurement. $\mathrm{f}_{\mathrm{pw}}$ and $\mathrm{f}_{\mathrm{bw}}$ have the limitation of following conditions.

$$
\begin{aligned}
& 0 \leqq \mathrm{f}_{\mathrm{pw}} \leqq 1 \\
& 0 \leqq \mathrm{f}_{\mathrm{bw}} \leqq 1
\end{aligned}
$$

Relation as shown in eqs. (8) (12) being imposed by conditions eqs.(13) and (14), is shown in Fig. 4.

For the low PTFE volume fraction samples that contain $20 \%$ or $40 \%$ PTFE, $f_{p w}$ and $f_{b w}$ were found to be 1 . This means that for these samples, surface of both binder and PTFE particle is perfectly covered by water. For $60 \%$ PTFE contained sample, $\mathrm{f}_{\mathrm{pw}}$ is between 0.59 and 0.19 and $\mathrm{f}_{\mathrm{bw}}$ is between 1 and 0 . For $80 \%$ PTFE contained sample, $f_{p w}$ is between 0.22 and 0.07 and $f_{b w}$ is between 1 and 0 . For $90 \%$ PTFE contained sample, $\mathrm{f}_{\mathrm{pw}}$ is between 0.20 and 0.13 and $f_{b w}$ is between 1 and 0 . These results show the area of PTFE surface covered by water decreases with

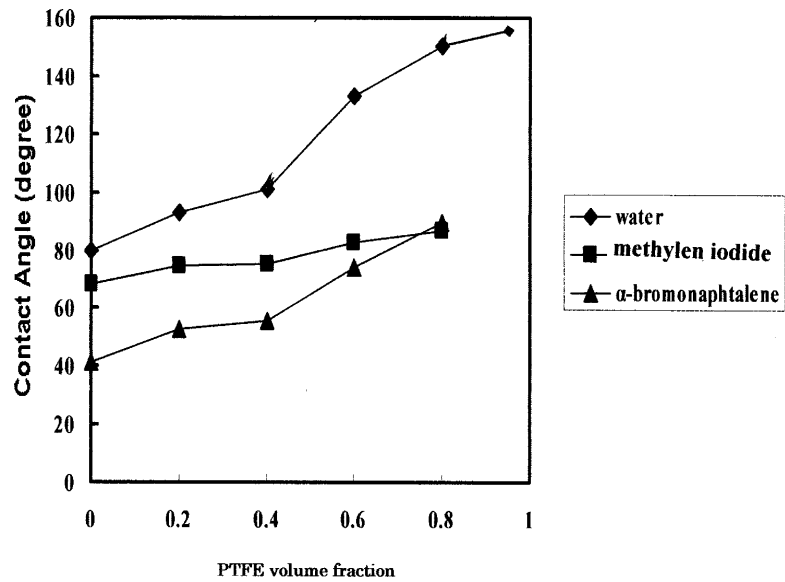

Fig. 3 Contact angle of water, methylene iodide and $\alpha$-bromonaphtalene on the water repellent material. 
the increase of the PTFE volume fraction while the surface of binder can be covered by water completely. In Fig. 4, the gradient of $f_{b w}-f_{p w}$ lines decreases with increasing PTFE volume fraction. In other words, the area of PTFE covered by air increases with the increase of the PTFE volume fraction.

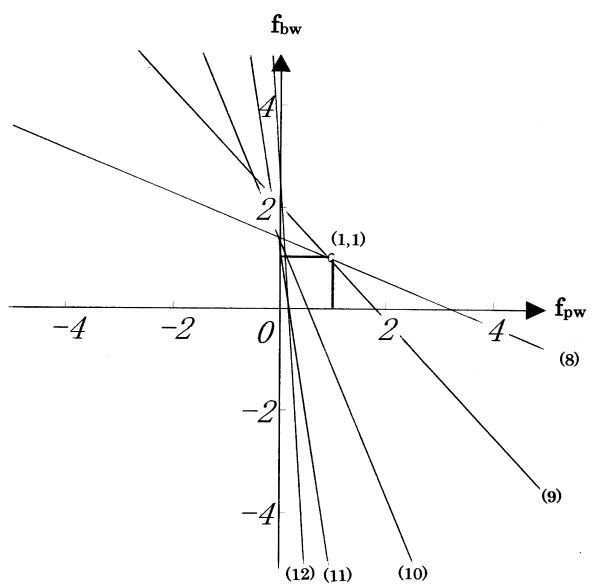

Fig. 4 The relation between $\mathrm{f}_{\mathrm{pw}}$ and $\mathrm{f}_{\mathrm{bw}}$ for water on the water repellent material. Lines(8)-(12) correspond to eq. (8)-(12).

\subsection{Contact angle of methylene iodide}

As shown in Fig. 3, the contact angle of methylene iodide increases with increasing PTFE volume fraction. In the case of methylene iodide, the formula (6) in the former section contains the parameters of $f_{p m}$ and $f_{b m}$. By substituting experimental value of the contact angle of methylene iodide, $85.4^{\circ}$ for $\theta_{\mathrm{pm}}$ and $68.5^{\circ}$ for $\theta_{\mathrm{bm}}$, corresponding experimentally observed contact angle for $\theta_{\text {as }}$, the relation of unknown parameters $f_{p m}$ and $f_{b m}$ is obtained as following.

$$
\begin{array}{ll}
f_{b m}=-0.59 f_{p m}+1.63 \text { for } & f_{p}=0.2 \\
f_{b m}=-1.59 f_{p m}+2.76 \text { for } & f_{p}=0.4 \\
f_{b m}=-3.55 f_{p m}+4.54 \text { for } & f_{p}=0.6 \\
f_{b m}=-9.50 f_{p m}+10.1 \text { for } & f_{p}=0.8
\end{array}
$$

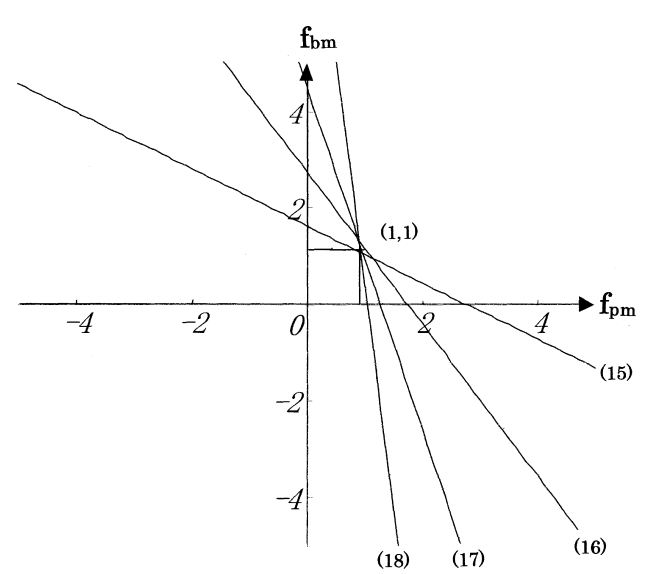

Fig. 5 The relation between $\mathrm{f}_{\mathrm{pm}}$ and $\mathrm{f}_{\mathrm{bm}}$ for methylene iodide on the water repellent material. Lines (15) (18) correspond to eq. (15) (18). $f_{p m}$ and $f_{b m}$ have the limitation of following conditions

$$
\begin{aligned}
& 0 \leqq \mathrm{f}_{\mathrm{pm}} \leqq 1 \\
& 0 \leqq \mathrm{f}_{\mathrm{bm}} \leqq 1
\end{aligned}
$$

Relation (15) (18) being imposed by conditions (19) and (20), is shown in Fig. 5.

Different from Fig. 4 for water, $\mathrm{f}_{\mathrm{pm}}$ and $\mathrm{f}_{\mathrm{bm}}$ for methylene iodide are found to be 1 . This means both PTFE and binder are covered thoroughly by methylene iodide for all the PTFE volume fraction.

\subsection{Contact angle of $\alpha$-bromonaphtalene}

The contact angle of $\alpha$-bromonaphtalene increases with increasing PTFE volume fraction as shown in Fig. 3. In the case of $\alpha$-bromonaphtalene, the formula (6) in the former section contains the parameters of $\mathrm{f}_{\mathrm{p} \alpha}$ and $\mathrm{f}_{\mathrm{b} \alpha}$. By substituting experimental values of the contact angle of $\alpha$-bromonaphtalene, $67.6^{\circ}$ for $\theta_{\mathrm{p} \alpha}$ and $41.3^{\circ}$ for $\theta_{\mathrm{b} \alpha}$, corresponding experimentally observed contact angle for $\theta_{\text {as }}$, the relation of unknown parameters $f_{p \alpha}$ and $f_{b \alpha}$ is obtained as following.

$$
\begin{array}{llll}
f_{b \alpha}=-0.59 f_{p \alpha}+1.60 & \text { for } & f_{p}=0.2 \\
f_{b \alpha}=-1.58 f_{p \alpha}+2.68 & \text { for } & f_{p}=0.4 \\
f_{b \alpha}=-3.54 f_{p \alpha}+4.00 & \text { for } & f_{p}=0.6 \\
f_{b \alpha}=-9.44 f_{p \alpha}+7.48 & \text { for } & f_{p}=0.8
\end{array}
$$

$\mathrm{f}_{\mathrm{p} \alpha}$ and $\mathrm{f}_{\mathrm{b} \alpha}$ have the limitation of following conditions.

$$
\begin{aligned}
& 0 \leqq \mathrm{f}_{\mathrm{p} \alpha} \leqq 1 \\
& 0 \leqq \mathrm{f}_{\mathrm{b} \alpha} \leqq 1
\end{aligned}
$$

Relations (21) (24) being imposed by conditions (25) and (26), is shown in Fig. 6.

For the low PTFE volume fraction samples that contain $20 \%$ or $40 \%$ PTFE, $f_{p \alpha}$ and $f_{b \alpha}$ were found to be 1 . This means that for these samples, surface of both binder and PTFE particle is perfectly covered by $\alpha$-bromonaphtalene. For $60 \%$ PTFE contained sample, $\mathrm{f}_{\mathrm{p} \alpha}$ is between 1 and 0.85 and $f_{b \alpha}$ is between 1 and 0 . For $80 \%$ PTFE contained sample, $\mathrm{f}_{\mathrm{p} \alpha}$ is between 0.79 and 0.69 and $\mathrm{f}_{\mathrm{b} \alpha}$ is between 1 and 0 .

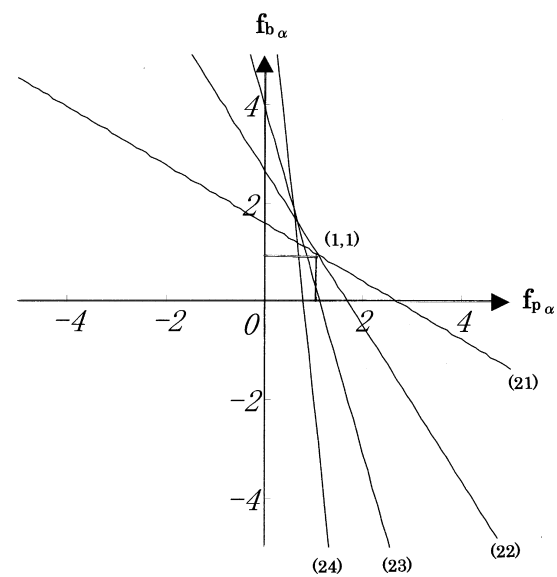

Fig. 6 The relation between $\mathrm{f}_{\mathrm{p} \alpha}$ and $\mathrm{f}_{\mathrm{b} \alpha}$ for $\alpha$ bromonaphtalene on the water repellent material. Lines (21) (24) correspond to eq. (21) (24). 
These results show the area of PTFE surface covered by $\alpha$-bromonaphtalene decreases with the increase of the PTFE volume fraction while the surface of binder can be covered by $\alpha$-bromonaphtalene completely.

In Fig. 6, the gradient of $\mathrm{f}_{\mathrm{b} \alpha}-\mathrm{f}_{\mathrm{p} \alpha}$ line decreases with increasing PTFE volume fraction. In other words, the area of PTFE covered by air increases with the increase of the PTFE volume fraction.

\section{Discussion}

The formula (6) that expresses the contact angle $\theta_{\text {as }}$ of a particulate composite material, is function of $\mathrm{f}_{\mathrm{p}}, \mathrm{f}_{\mathrm{pw}}$ and $\mathrm{f}_{\mathrm{bw}}$. As shown in previous section, the relation between $f_{p w}$ and $f_{b w}$ can be obtained by substituting the experimental data for $\theta_{\text {as }}$ in formula (6). As PTFE is hydrophobic and binder is hydrophilic, the relation $\mathrm{f}_{\mathrm{pw}}<\mathrm{f}_{\mathrm{bw}}$ exists.

It is plausible to assume $\mathrm{f}_{\mathrm{bw}}=1$.

Then $\theta_{\text {as }}$ is a function of $\mathrm{f}_{\mathrm{p}}$ and $\mathrm{f}_{\mathrm{pw}}$ in formula (6).

$\theta_{\mathrm{as}}-\mathrm{f}_{\mathrm{p}}-\mathrm{f}_{\mathrm{pw}}$ relation is calculated as shown in Fig. 7 . In the same manner, by assuming $f_{b m}=1$ for methylene iodide and $\mathrm{f}_{\mathrm{b} \alpha}=1$ for $\alpha$-bromonaphtalene, $\theta_{\mathrm{as}}-\mathrm{f}_{\mathrm{p}}-\left(\mathrm{f}_{\mathrm{pm}}, \mathrm{f}_{\mathrm{p} \alpha}\right)$ relations are calculated as shown in following Figs. 8 9 which are explained in the following sections.

\subsection{Contact angle of water}

Fig. 4 helps to understand the reason why the water repellent particulate composite material exhibits higher contact angle for the higher PTFE volume fraction for water. Assuming $\mathrm{f}_{\mathrm{bw}}=1, \theta_{\mathrm{as}}-\mathrm{f}_{\mathrm{p}}-\mathrm{f}_{\mathrm{pw}}$ relation is skeptically expressed by Fig. 7 .

When PTFE volume fraction is small, the experimental value of $\theta_{\text {as }}$ goes forward the edge of $\theta_{\text {as }}-f_{p w}-f_{b w}$ surface and then climbs up this surface to reach the high $\theta_{\text {as }}$ value as PTFE volume fraction increases.

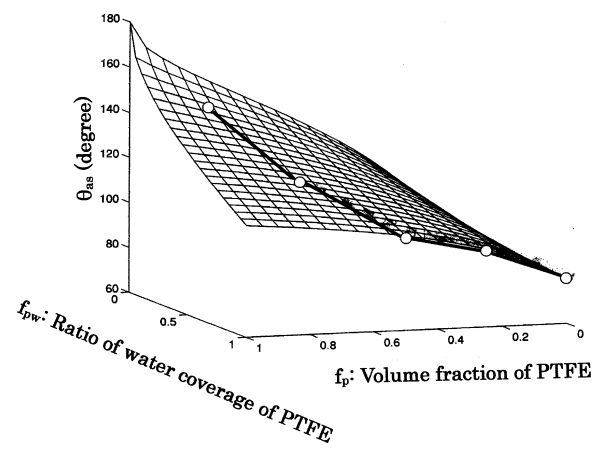

Fig. 7 The contact angle $\theta_{\text {as }}$ of water as a function of PTFE volume fraction $f_{p}$ and PTFE coverage of water $\mathrm{f}_{\mathrm{pw}}$

\subsection{Contact angle of methylene iodide}

In Fig. $5, f_{b m}-f_{p m}$ lines pass through $(1,1)$ point. The contact angle of methylene iodide on the water repellent particulate composite material fits well with the theoretical values for $\mathrm{f}_{\mathrm{pm}}=1$ and $\mathrm{f}_{\mathrm{bm}}=1$ for all volume fraction of PTFE from 0 to $100 \%$, as shown in Fig. 8.

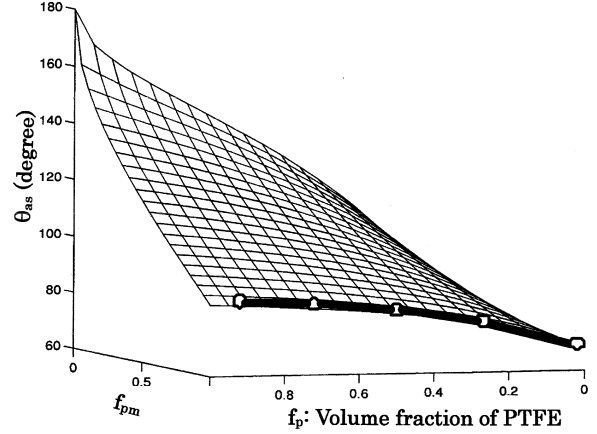

Fig. 8 The contact angle $\theta_{\text {as }}$ of methylene iodide as a function of PTFE volume fraction $f_{p}$ and PTFE coverage of methylene iodide $\mathrm{f}_{\mathrm{pm}}$.

As far as methylene iodide is concerned, the contact angle of methylene iodide on the PTFE particulate composite materials for all PTFE volume fractions can be explained by the simple average of methylene iodide contact angles on PTFE and binder, following Cassie's formula. ${ }^{11)}$ In case of methylene iodide, no air exists between methylene iodide droplet and the water repellent particulate composite material, different from water case. This is skeptically expressed by Fig. 8 .

\subsection{Contact angle of $\alpha$-bromonaphtalene}

Fig. 6 helps to understand the reason why the water repellent material with higher PTFE volume fraction exhibits higher contact angle of $\alpha$-bromonaphtalene. Assuming $\mathrm{f}_{\mathrm{b} \alpha}=1, \theta_{\mathrm{as}}-\mathrm{f}_{\mathrm{p}}-\mathrm{f}_{\mathrm{p} \alpha}$ relation is skeptically expressed by Fig. 9 .

When PTFE volume fraction is small, the experimental value of $\theta_{\text {as }}$ goes forward the edge of $\theta_{\mathrm{as}}-\mathrm{f}_{\mathrm{p} \alpha}-\mathrm{f}_{\mathrm{b} \alpha}$ surface and then climbs up this surface to reach the high $\theta_{\text {as }}$ value as PTFE volume fraction increases.

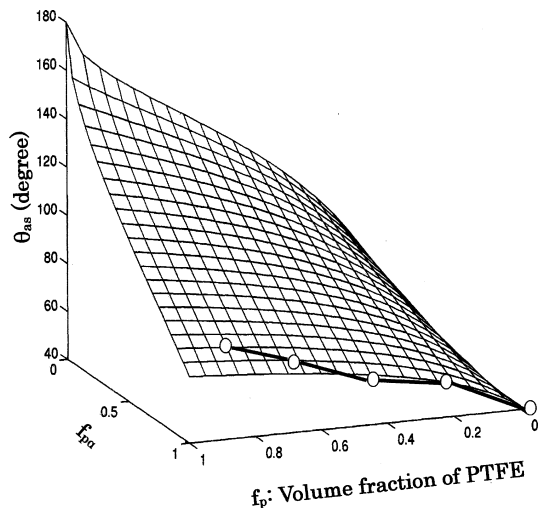

Fig. 9 The contact angle $\theta_{\text {as }}$ of $\alpha$-bromonaphtalene as a function of PTFE volume fraction $\mathrm{f}_{\mathrm{p}}$ and PTFE coverage of $\alpha$-bromonaphtalene $\mathrm{f}_{\mathrm{p} \alpha}$.

\section{Conclusion}

The contact angle of three different types of liquid each of which has different composition of dispersion, polar and hydrogen bonding components of surface free 
energy on the PTFE particulate composites, was measured to examine the validity of the derived formula (6) that expresses the contact angle of liquid on the PTFE particulate composites material.

By substituting the experimental data of contact angle of water, methylene iodide and $\alpha$-bromonaphtalene to the formula, the relations of $f_{p w}$ and $f_{b w}$ for water, $f_{p m}$ and $\mathrm{f}_{\mathrm{bm}}$ for methylene iodide, $\mathrm{f}_{\mathrm{p} \alpha}$ and $\mathrm{f}_{\mathrm{b} \alpha}$ for $\alpha$-bromonaphtalene, which show the coverage of PTFE by liquid and that of binder by liquid respectively, were obtained. From these relations, results for water, methylene iodide and $\alpha$-bromonaphtalene were obtained as follows.

The area of PTFE surface covered by water decreases with the increase of the PTFE volume fraction while the surface of binder can be covered by water completely.

Both PTFE and binder are covered thoroughly by methylene iodide for all the PTFE volume fraction.

The area of PTFE surface covered by $\alpha$-bromonaphtalene decreases with the increase of the PTFE volume fraction while the surface of binder can be covered by $\alpha$ bromonaphtalene completely.

By assuming $\mathrm{f}_{\mathrm{bw}}=1$, which is plausible because $\mathrm{f}_{\mathrm{pw}}<\mathrm{f}_{\mathrm{bw}}$, the relations of $\theta_{\mathrm{as}}-\mathrm{f}_{\mathrm{p}}-\left(\mathrm{f}_{\mathrm{pw}}, \mathrm{f}_{\mathrm{pm}}, \mathrm{f}_{\mathrm{p} \alpha}\right)$ can be skeptically expressed. The contact angle of three different types of liquid on the PTFE particulate composites material, was explained by the derived formula (6)

\section{References}

1) G. Yamauch, H. Saito and K. Takai, "PTFE Based Water Repellent Coating for Communication Antennas”, IEICE Transactions, Vol.E83-C, No.7, pp.1139-1141 (2000).

2 ) H. Saito, K. Takai, H. Takazawa and G. Yamauchi, "A Study on Snow Sticking Weight to Water Repellent Coating”, Material Science Research International, Vol.3, No.4, pp.216-219 (1997).

3 ) H. Saito, K. Takai and G. Yamauchi, "Water and IceRepellent Coatings", Surface Coatings International, B, Vol.80, No.4, pp.168-171 (1997).

$4)$ G. Yamauchi, J. D. Miller, H. Saito, K. Takai, Ueda, H. Takazawa, H. Yamamoto and S. Nishi, "Wetting Characteristics of Newly Developed Water-Repellent Material”, Colloids and Surfaces A : Physicochemical and Engineering Aspects, Vol.116, pp.125-134 (1996).
$5)$ G. Yamauchi, J. D. Miller, H. Saito, K. Takai, Ueda, H. Takazawa, H. Yamamoto and S. Nishi, "Wetting Characteristics of Newly Developed Water Repulsive material”, 69th Colloid \& Surface Science Symposium of American Chemical Society, Salt Lake City, pp.89-95 (1995).

$6)$ G. Yamauchi, Y. Riko, Y. Yasuno, T. Shimizu and N. Funakoshi, "Water Reppellent Coatng for Mobile Phone Microphone”, Nano and Hybrid Coatings, Manchester, U. K., Paper 20, pp.1-6 (2005).

7) Y. Yasuno, Y. Riko, N. Funakoshi, T. Shimizu and G. Yamauchi, "Environmentary Robust Electret Condenser Microphone”, IEICE Transaction, Fundamentals, Vol.E-89A, No.8, pp.2226-2229 (2006).

$8)$ G. Yamauchi, K. Yamauchi, K. Ikeda and T. Shimizu, "Ndoped $\mathrm{TiO}_{2}$ added Water Repellent and Contamination Free Material", Coating Science International 2008, Noordwijk, The Netherlands, pp.220-222 (2008).

$9)$ G. Yamauchi, J. D. Miller, H. Saito, K. Takai, H. Takazawa and T. Ueda, "The Wetting Characteristic of PTFE Particulate Composites", Materials Transactions, Japan Institute of Metals, Vol.37, No.4, pp.721-728 (1996).

10) R. N. Wentzel, Industrial \& Engineering Chemistry, Vol.28, pp.988-994 (1936)

11) A. B. D. Cassie, Discussion of the Faraday Society, Vol.3, pp.11-16 (1948).

12) T. Young, Miscellaneous Works, Vol.1, G.Peacock ed., London, Murray, p.418 (1855)

13) S. Veeramasuneni, J. Drelich, J. D. Miller and G. Yamauchi, "Hydrophobicity of ion-plated PTFE coatings", Progress in Organic Coatings, Vol.31, pp.265-270 (1997).

14) A. Bunde and S. Havlin, "Fractals in Science", SpringerVerlag, Berlin, pp.1-25 (1994).

15) T. Onda, S. Shibuichi, N. Satoh and K. Tsujii, "Superwater-repellent fractal surfaces”, Langmuir, Vol.12, pp.21252127 (1996).

16) J. Bico, U. Thiele and D. Quere, "Wetting of textured surface”, Colloids and Surfaces A : Physicochemical and Engineering Aspects, Vol.206, Issues 1-3, pp.41-46 (2002).

17) Y. Kitazaki and T. Hata, "Extension of Fowkes' Equation and Estimation of Polimer Solid”, Japan Adhesion Society, Vol.8, No.3, pp.131-141 (1972) (In Japanese). 